\title{
Lo más fresco de la Florida: Lechugas ${ }^{1}$
}

\author{
Claudia Peñuela ${ }^{2}$
}

\section{Datos nutricionales}

\section{Las lechugas de Florida son:}

$\checkmark$ Altas en vitamina A con excepción de la lechuga tipo crisphead. La

vitamina $A$ ayuda a mantener una visión normal, una piel saludable y a proteger contra las infecciones.

$\checkmark$ Altas en vitamina $K$, la cual ayuda al buen crecimiento de los huesos

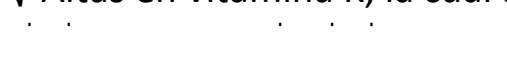

$\checkmark$ Buena fuente de vitamina $C$, la cual ayuda a curar las cortadas, heridas y a mantener saludables los dientes y encías.

$\checkmark$ Buena fuente de folato. El folato es necesario para la formación de células sanguíneas y reducción del riesgo en las mujeres embarazadas de tener un niño con defectos cerebrales o espina bífida.

$\checkmark$ Fuente de fibra. La fibra reduce el riesgo de enfermedades del corazón. $\checkmark$ Naturalmente libres de grasa, colesterol y bajas en calorías y sodio.

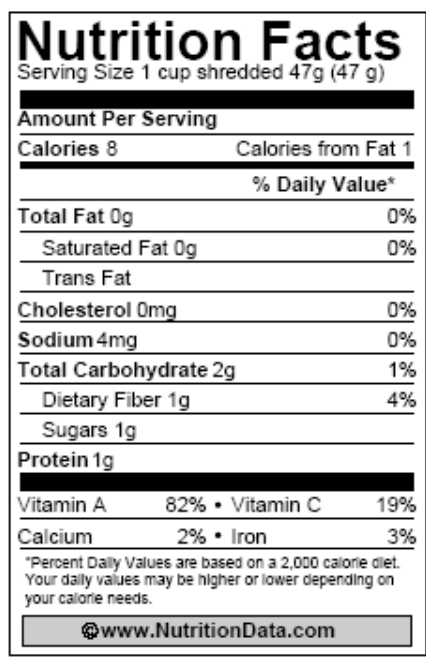

Nota: Hay cuatro tipos de lechugas: La lechuga orejona (romaine) tiene hojas largas y de color verde oscuro. La lechuga batavia (butterhead), tiene textura mantecosa y cogollo suelto. La lechuga crisphead tiene hojas color verde claro y cogollo apretado. La lechuga looseleaf no tiene cogollo, sus hojas están unidas al tallo.

\section{¿Por qué comprar localmente?}

El Departamento de Agricultura de los Estados Unidos (USDA, por sus siglas en inglés) estima que el promedio de viaje de los productos agrícolas desde su origen hasta los mercados locales del agricultor es de solo $\mathbf{5 0}$ millas, comparado con 2,000 millas hasta los supermercados.

Compre localmente y obtenga estos beneficios:

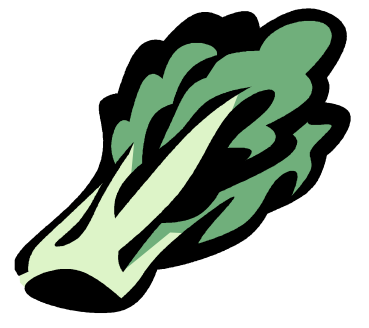

Frescura y nutrición. Las frutas y verduras cosechadas en su punto tienen mejor sabor y características nutricionales.

Social/cultural. Ayuda a la comunidad a estar consciente de la importancia de la agricultura.

$>$ Ambiental. Protege los recursos naturales como espacios verdes, fauna, flora, agua, aire y suelos.

$>$ Económico. Promueve la fuerza laboral local.

1. Este documento FCS 8879-Span, es uno de una serie del Departamento de Ciencias de la Familia, la Juventud y la Comunidad, Servicio de Extensión Cooperativa de la Florida, Instituto de Alimentos y Ciencias Agrícolas, Universidad de la Florida. Fecha primera publicación: agosto 2009. Visite nuestro sitio web EDIS en http://edis.ifas.ufl.edu.

2. Claudia Peñuela, asistente en nutrición-EFNEP, Departamento de Ciencias de la Familia, la Juventud y la Comunidad, Servicio de Extensión Cooperativa, Instituto de Alimentos y Ciencias Agrícolas, Universidad de la Florida, Gainesville, Florida 32611.

El Instituto de Alimentos y Ciencias Agrícolas es una institución con igualdad de oportunidades, autorizado a proveer investigación, información educativa y otros servicios, únicamente a los individuos e instituciones que operan sin discriminación alguna con relación a la raza, credo, color, religión, edad, i ncapacidad, sexo, orientación se xual, e stado ci vil, nacionalidad, o pinión política o af iliaciones. E I Departamento de Agricultura d e I os Estados Unidos, Servicio de Extensión Cooperativa, Universidad de la Florida, IFAS, Florida A. \& M. Programa de Extensión Cooperativa y Juntas de Comisionados del Condado en la cooperación. Millie Ferrer-Chancy, Decana Interina. 


\section{¿Dónde se cosechan las lechugas de Florida?}

Las lechugas se cosechan en todo el estado de Florida.

\section{¿Cuándo puede comprar lechugas en Florida?}

Puede comprar lechugas desde noviembre hasta mayo. ¡Durante siete meses del año!

\begin{tabular}{|l|l|l|l|l|l|l|l|l|l|l|l|}
\hline ENE & FEB & MAR & ABR & MAY & JUN & JUL & AGO & SEP & OCT & NOV & DIC \\
\hline
\end{tabular}

\section{Seleccione}

$\checkmark$ Lechugas tipo crisphead y romaine pesadas para su tamaño y con hojas crujientes y firmes.

$\checkmark$ Lechugas tipo butterhead y looseleaf que tengan hojas suaves.

$\checkmark$ Lechugas brillantes (verde oscuro hasta verde claro). Las verde oscuro contienen más cantidad de nutrientes y de antioxidantes.

$\checkmark$ Lechugas de diferente tipo para un mayor balance nutricional.

$\checkmark$ Lechugas que no tengan hojas secas.

$\checkmark$ Lechugas que no tengan hojas marchitas, ni pardas o amarillentas.

\section{Lechugas frescas de la Florida: del mercado a la mesa}

Ensalada agridulce de hojas verdes

5 tazas de lechuga romaine en pedazos

3 tazas de espinaca

2 tazas de champiñones rebanados

2 naranjas peladas y en gajos

1 taza de ciruelas deshuesadas

$1 / 2$ taza de cebolla roja en rebanadas

$1 / 2$ taza de aderezo de mostaza y miel sin grasa

$1 / 4$ cucharadita de pimienta negra

\section{Rinde: 4 Porciones Tiempo: 10 minutos}

Mezclar todos los ingredientes en un recipiente grande.

* Información nutricional por porción: Calorías: (1/4 receta): 190 cal; Grasa 1g; Sodio 310 mg; Carbohidratos 47g; Fibra 7g; Proteína 4g; Vitamina A 130\%; Vitamina C 110\%; Calcio 10\%; Hierro 10\%. *El \% del valor diario de vitamina $A$, vitamina $C$, calcio y hierro está basado en una dieta de 2,000 calorías.

Adaptado de: $\underline{\text { http://apps.nccd.cdc.gov/dnparecipe/recipesearch.aspx }}$

Ensalada de Florida

1 taza de lechuga romaine, en pedazos

$1 / 2$ taza de escarola picada

$1 / 2$ taza de endivia picada

1 rama de cilantro picado

1 aguacate pelado y rebanado

1 pepino pelado y rebanado

4 rábanos rebanados
2 zanahorias peladas y en rodajas

1 pimentón verde, sin semillas y picado

1 naranja, pelada y en gajos

$1 / 2$ taza de col rizada picada

$1 / 2$ taza de fresas picadas

$1 / 2$ taza de tomates cherry enteros

\section{Rinde: 8 Porciones}

Mezclar todos los ingredientes en un recipiente grande. Escoja un aderezo bajo en grasa.

Información nutricional por porción: (Sin aderezo): Calorías: 95 cal; Grasa $3 \mathrm{~g}$; Carbohidratos $9 \mathrm{~g}$; Fibra $1 \mathrm{~g}$; Proteína $0 \mathrm{~g}$ 